\title{
O teatro dos sentidos: a unidade dramática nos lais de Marie de France (Século XII)
}

\section{The theater of the senses: the dramatic unity in the lais of Marie de France (12th century)}

Constantino Luz de Medeiros

Universidade Federal de Minas Gerais, Belo Horizonte, Minas Gerais / Brasil constantinoluz@usp.br

Resumo: O presente artigo analisa a questão da unidade dramática na composição dos lais de Marie de France (século XII) e sua inserção na tradição da literatura românica medieval. O objetivo é discutir como a restrição da narrativa a um episódio significativo, a economia nas descrições de personagens, a direcionalidade do narrado e a inserção do maravilhoso, elementos centrais dos lais, contribuem para a sustentação da unidade dramática dessa forma breve poética medieval românica, o que a caracteriza como antecedente das formas breves modernas.

Palavras-chave: Lais; Marie de France; formas breves românicas medievais; unidade dramática.

Abstract: This paper analyses the question of the dramatic unity in the composition of the lais of Marie de France (12th century) and its insertion in the tradition of the medieval romance literature. Its main objective is to discuss how the restriction of the narrative to a significant episode, the economy in the descriptions of the characters, the directionality of the narrated and the insertion of the marvelous, which are central aspects of the lais, contribute to the conservation of the dramatic unity of this romance medieval poetic short form, characterizing it as an antecedent of the modern short forms.

Keywords: Lais; Marie de France; romance medieval short forms; dramatic unity. 
Recebido em: 18 de abril de 2017. Aprovado em: 12 de junho de 2017.

\section{Introdução}

O alvorecer do século XII marca o início de uma época ímpar na história da literatura românica medieval. Nesse período de efervescência cultural, as formas breves poéticas de cunho narrativo, tais como os lais de Marie de France, são exemplos de narrativas nas quais já se podem vislumbrar certos procedimentos que indicam algum grau de unidade e certa elaboração autoral. Marie de France escreveu seus versos durante a época em que florescia o romance de cavalaria. Expressão pessoal de tradição oral, os lais da autora francesa contribuíram para o aprimoramento da tradição de narrativas breves que abrem caminho para a novela e o conto, principalmente através da narração autoral de episódios significativos. Definido como uma pequena narrativa em verso, os lais geralmente desenvolvem alguma intriga romanesca, na qual o tema do amor prevalece. Entre os doze lais atribuídos a Marie de France, as aventuras fazem parte de uma estrutura que vai quase sempre da infelicidade e sofrimento amorosos ao final feliz. Escritos em versos octossílabos, os lais abordam temas que circulam tanto na Bretanha, quanto na România, e que serão assimilados mais tarde pelas novelas de Giovanni Boccaccio (1313-1375), Geoffrey Chaucer (1343-1400), e por outras coletâneas de narrativas breves medievais, como as Cent nouvelles nouvelles compiladas pelo Duque de Borgonha, em 1462. As composições de Marie de France pertencem a um período em que as formas breves começam a se elaborar, ainda que o núcleo central ao redor do qual se concentra toda a narrativa não esteja tão definido como estará, um século e meio mais tarde, na coleção de novelas do Decamerão de Giovanni Boccaccio. Seus versos fazem a mesma defesa de valores e qualidades essenciais do universo simbólico das narrativas de cavalaria, tais como a necessidade do amor (Guigemar), as qualidades da lealdade (Madressilva), generosidade (Yonec), sacrifício pessoal, alegria em viver, a exaltação dos presentes de amor e a crítica severa ao amor apenas pelo interesse próprio (FERRANTE, 2001, p. 52).

O período de 340 anos que separa as primeiras obras em francês, como os Serments de Strasbourg (842) e a Cantilène ou Séquence de Sainte Eulalie (882) e os primeiros lais e fabliaux, no final século XII, 
caracteriza-se principalmente por obras que exteriorizam adaptações de textos religiosos latinos (POTTIER, 1964, p. 14). Como demonstra Ernst Hoepffner (1935, p. 5, tradução nossa), "são três séculos de esforços pacientes e desenvolvimentos lentos", nos quais a narrativa autoral vai se descolando aos poucos das narrativas religiosas. Entre os séculos XI e XII, com as narrativas maravilhosas que afluíram à Europa advindas tanto do Oriente, através dos árabes, como do Norte, por influência dos celtas, bretões e irlandeses, surgem novas formas de composição poética, as quais diferem das canções de gesta primitivas. São composições feitas em versos octossílabos que se exteriorizam através de clérigos jograis e menestréis pela França (HOEPFFNER, 1935, p. 9). Em termos de audiência, de acordo com Ferrante (2001, p. 50), o público dos lais de Marie de France é o mesmo que fruía das narrativas de Chrétien de Troyes e das primeiras versões escritas da história de Tristão e Isolda, ou seja, a corte que falava francês, embora algumas de suas composições, por conterem palavras de origem inglesa, pudessem sugerir igualmente que se tratasse de audiência composta por normandos na Inglaterra.

Entre os aspectos fundamentais da estrutura dos lais, a questão da unidade dramática está relacionada ao efeito necessário para que essas formas breves românicas medievais pudessem ser executadas oralmente em tempo e espaço determinados, daí a importância da justaposição entre o tempo de ação e o tempo da narrativa (ZUMTHOR, 1972, p. 390). O presente artigo analisa a questão da unidade dramática nos lais de Marie de France (século XII) e sua inserção na tradição das formas breves românicas medievais. O objetivo é discutir como a restrição da narrativa a um episódio significativo, a economia nas descrições de personagens e a direcionalidade do narrado, elementos centrais dos lais, contribuem para a manutenção da unidade dramática, o que caracteriza essa forma breve como antecedente das formas breves modernas.

\section{0 teatro dos sentidos ${ }^{1}$}

Bele amie, si est de nus

Ne vus sanz mei, ne jeo sanz vus

Marie de France ${ }^{2}$.

\footnotetext{
${ }^{1}$ A expressão é de Danielle Régnier-Bohler (2012, p. 325).

2 "Bela amiga, assim ocorre conosco: nem vós sem mim, nem eu sem vós" (MARIE DE FRANCE apud FURTADO, 2001, p. 33).
} 
Quando o papa Urbano II, no ano de 1095, acende o fogo da primeira cruzada no Concílio de Clermont-Ferrand, principia um tempo de aventuras, migrações e lendas guerreiras que se concretiza em uma das épocas de maior intercâmbio cultural entre os povos da Europa (LE GOFF, 2002, p. 66). Esse tempo de peregrinações e cruzadas culmina na primeira grande obra-prima da literatura francesa, a Canção de Rolando. Entre o começo do século XI e as décadas finais do século XII, quando surgem os lais de Marie de France, muita coisa se alterou em termos de criação artística e consciência narrativa. Das canções singelas que entoavam os bravos feitos dos heróis nas batalhas, e dos relatos das guerras travadas entre os cristãos e os mouros, até esse pequeno poema em octossílabos que fala de amor e de ternura, ocorre uma mudança não apenas no tratamento da matéria narrada, mas também no uso de diversos procedimentos literários, os quais têm entre seus objetivos principais a manutenção da unidade dramática. A sustentação da tensão narrativa nos lais - decorrente de sua origem oral - está diretamente relacionada ao recorte do acontecimento significativo, para o qual todos os detalhes da narrativa apontam. O episódio significativo, ou seja, a narrativa de acontecimento individual que se destaca do todo de uma obra, tem uma tradição muito antiga. Esse tipo de fenômeno pode ser encontrado nas mais diversas narrativas desde a mais remota Antiguidade. Nos episódios das epopeias de Homero é possível destacar diversos momentos nos quais esse procedimento parece surgir, como na chamada ira de Aquiles, na Ilíada, ou no episódio em que Odisseu conhece o país dos Feaces (ou Feácios), na Odisseia. A conhecida cena do Banquete de Trimalquião, no Satíricon, de Tito Petrônio Árbitro (27-66 d. C.) é outro exemplo de narrativa que se destaca do conjunto de relatos, evidenciando o episódio significativo. ${ }^{3}$ As narrativas de autores como Petrônio demonstram o desenvolvimento artístico do recorte do episódio significativo enquanto procedimento literário. A distância que separa a obra de Petrônio dos lais de Marie de France indica grandes alterações no que concerne a narrativa e as formas breves, bem como no modo pelo qual o amor é retratado. A mudança do interesse coletivo (combater em nome de Deus, pela glória do Rei e da terra) para o desejo individual (conquistar o amor da amada), acompanha a profunda transformação na estrutura social do mundo laico, e na visão do amor e da mulher:

${ }^{3}$ Sobre o episódio significativo na tradição literária e no Satíricon de Petrônio, ver AQUATI apud PETRÔNIO, 2008, p. 223; AUERBACH, 2004, p. 21. 
Nessa sociedade cortesã, a mulher, como acabamos de ver, aparece como a primeira e principal inspiração da renovação literária e, assumindo o lugar central, se torna o tema das homenagens poéticas e o objetivo central das ações heróicas. Quem diz mulher, diz amor. A canção de gesta primitiva ignora o amor e a mulher. Rolando combate por seu Deus, por seu rei, por sua glória. Ele sonha com a "doce França", mas seu pensamento jamais se volta para Aude, sua noiva, que lhe espera angustiada em Aix, e que morre de dores com a notícia de sua morte (DUBUIS, 1973, p. 313, tradução nossa).

Como consequência da delimitação mais clara do episódio narrado, uma das características fundamentais dos lais é a de apresentar uma concentração dramática maior. Além dos temas do amor e da traição amorosa, a matéria tratada era diversa, abrangendo as juras e traições amorosas, as rivalidades familiares, os trajes, os lugares simbólicos, a angústia de um mundo deserto, o homem solitário, o pomar, a linguagem secreta dos sinais, a palavra proibida, a apaixonada busca pelo pai, entre muitos outros. Paul Zumthor (1972, p. 384) observa que há seis partes constitutivas nos lais de Marie de France, as quais podem ser consideradas como as fases sucessivas na performance oral dessa narrativa breve. As duas primeiras etapas tratam de conferir verossimilhança ao narrado. Primeiro, a descrição do espaço, geralmente um bosque ou floresta conhecida, ou grande habitação de nobre. Em segundo lugar, Marie recorre ao topos da aventura que lhe chega a partir de antigos relatos, como no Lai Chievrefoil ou Chèvrefeuille (Madressilva): "Vários me contaram sobre a estória de Tristão e da rainha, e a encontrei também em forma escrita" (MARIE DE FRANCE apud FURTADO, 2001, p. 131). O terceiro passo reafirma o caráter aventureiro da narrativa, na qual tudo pode acontecer. Esse procedimento confere naturalidade ao surgimento do maravilhoso, como no Lai Lanval: "Contar-vos-ei agora a aventura de um outro lai, tal como ele ocorreu” (MARIE DE FRANCE apud FURTADO, 2001, p. 82). A seguir, Marie retoma o contexto da aventura, garantindo a verossimilhança de sua narrativa (ZUMTHOR, 2012, p. 12-13).

Outro procedimento literário utilizado pela autora para emprestar verossimilhança ao narrado e manter a tensão dramática de seu relato é a limitação do espaço no qual a história transcorre. Do mesmo modo que nas novelas de cavalaria, a restrição do encontro dos amantes a um 
espaço delimitado é parte integrante das estratégias narrativas dos lais. O bosque é lugar perfeito para esse teatro dos sentidos. Em suas fronteiras se aproximam o real e o maravilhoso, o estranho e o cotidiano. Como afirma Roger Dubuis (1973, p. 313), o bosque é lugar fechado, no qual se exalam as queixas de certas canções de fiar, lugar de espionar, lugar que deve, para escapar ao julgamento dos amores proibidos, cobrir-se de um silêncio mágico, onde desponta o maravilhoso, bem como os seres vindos do mundo "feérico" (das fadas). A natureza graciosa fornece o mote para o encontro amoroso. Desse modo, a floresta é o local ideal de reunião dos amantes, das juras de amor, lugar no qual se expõem os encantos da dama e a coragem do donzel, mas também propício à traição amorosa, como no Lai do Rouxinou:

Havia longo tempo que se amavam, quando, na chegada do verão, os bosques e prados reverdeceram e os vergéis abriram-se em flor; os passarinhos, com grande doçura, cantavam sua alegria por sobre as flores. Nessa atmosfera quem já amava com muito gosto, não é maravilha que agora se abandonasse ao amor. (MARIE DE FRANCE apud FURTADO, 2001, p. 112).

Apresentando uma extensão breve, com uma maior concentração lírica em suas narrações, o lai tinha como temática principal as penas e dificuldades do amor, incorporando inclusive o universo de lendas ainda mais antigas, como a de Tristão e Isolda. ${ }^{4}$ A composição desta forma breve já pressupõe e é gestada a partir de aventuras que misturam encontros e desencontros amorosos, paixões, traições e a presença do maravilhoso. $\mathrm{O}$ entremesclar do maravilhoso em meio a acontecimentos cotidianos, algo que se destaca nessa forma breve, indica o ponto de inflexão da narrativa, o momento em que a realidade e o fantástico se interpenetram nas aventuras, as quais devem ser, acima de tudo, "boas aventuras" (DUBUIS, 1973, p. 342). Alguns estudiosos, como Massaud Moisés (2004, p. 257), afirmam que os lais não eram acompanhados de instrumentos musicais, enquanto outros, a partir de descobertas mais recentes, inserem o uso de instrumento e do canto como forma de acompanhar ou mesmo de executar essa forma breve. Paul Zumthor (1972, p. 384) indica que muitos versos eram cantados e havia acompanhamento de harpa. Outros

\footnotetext{
${ }^{4}$ Para Fernando Carmona (1998, p. 86), a lenda de Tristão seria um arquétipo de referência lírica inevitável: "Tristão é o herói triste, o inventor místico da poesia amorosa, que vive, canta e morre de amor".
} 
autores consideram os lais originalmente composições musicais, como um son, no francês antigo. Jean-Pierre Aubrit (2002, p. 6, tradução nossa) define o lai como "um pequeno conto em versos que desenvolve uma intriga romanesca e no qual a narração prevalece sobre o sentido e que cultiva voluntariamente a emoção através de uma linguagem delicada". A referência à linguagem delicada é mais um dos elementos que indicam a relação entre os lais e a música:

Em sua origem, o lai é uma composição musical, um son, como se diz em francês antigo, executado na harpa ou na rota, que relata uma aventura, ou seja, um acontecimento mais ou menos maravilhoso. A partir dessa estrutura musical, o texto que deu origem a um gênero narrativo se destacou (MICHA, 1992, p. 7, tradução nossa).

O caráter performático dessa forma breve, advindo principalmente de sua difusão na forma oral, pressupõe certos elementos que mantenham seu ritmo e musicalidade, tais como a beleza das imagens, a concisão nas descrições e a centralidade do evento a ser narrado. Do mesmo modo, a hipótese de que os lais eram acompanhados de instrumentos musicais é corroborada pela própria autora. Ao final de seu Lai de Guigemar, Marie afirma: "Deste conto que ouviste foi composto o lai de Guigemar, que é acompanhado com harpa ou rota. A melodia é boa de escutar" (MARIE DE FRANCE apud FURTADO, 2001, p. 57). Pela menção à harpa e à rota (antigo instrumento de corda), conclui-se que os lais eram composições criadas para serem declamadas, ora acompanhados de música e ora não, a depender do sentimento e do momento da execução. $\mathrm{O}$ acompanhamento desses antigos instrumentos também poderia servir para introduzir e ambientar a narrativa, ao imitar os sons do bosque, dos pássaros silvestres, criando a atmosfera perfeita para que a audiência pudesse imaginar o encontro dos amantes. Assim, é possível entrever a existência de uma nova concepção narrativa que se caracteriza pela maior harmonização entre o lírico e o narrativo. Ao invés de simplesmente copiar ou incorporar modelos latinos, bretões ou celtas e tematizações estranhas ao seu mundo, Marie de France trabalha a matéria temática de forma a amalgamar, nos versos octossílabos, a beleza da narrativa oral, aliada à necessidade prática de fazer todos os elementos da narrativa se encaminharem para um desfecho único. Como se discute adiante, o recorte do episódio significativo é o núcleo ao redor do qual orbitam quase todos os elementos da narrativa. 


\section{A unidade dramática e o episódio significativo}

Em termos estruturais, os lais são narrativas breves de cunho lírico, compostas em versos, que narram aventuras e desventuras do amor e da paixão. Sua extensão pode variar entre os mais breves, contendo de 118 a 886 versos, como o Lai de Guigemar, até outros mais extensos, de 1182 versos. A concentração lírica, no entanto, é maior nos lais mais breves, tendendo os mais longos ao romanesco (DUBUIS, 1973, p. 326). Em razão de sua proximidade com outras formas breves poéticas de cunho narrativo medievais, e por sua estreita relação com a música, os lais desafiam a diferenciação com outras formas breves medievais, tais como o fabliau ${ }^{5}$. Narrativas de amor e de aventura, os lais se acercam do fabliau, com o qual dividem as diferentes denominações: aventura, conto, relato, causo, romança (CARMONA, 1998, p. 83). Há, todavia, entre as formas dos lais e do fabliau uma diferença no que concerne o trabalho com a economia do narrado, sendo o fabliau mais prolixo:

Assim como o fabliau, o lai é um gênero narrativo breve [...] Se a brevidade dos dois gêneros é da mesma ordem, por outro lado, há uma diferença considerável entre eles quando se examina a preocupação dos autores em justificar essa brevidade. Enquanto os autores dos fabliaux são prolixos, os autores dos lais são discretos (DUBUIS, 1973, p. 326, tradução nossa).

A unidade dramática nos lais de Marie de France está inteiramente relacionada ao recorte realizado pela autora em torno dos episódios significativos. A escolha do acontecimento a ser narrado ocorre já no primeiro momento da recitação dos lais da autora, como no Lai de Milun: "Aqui começarei Milun, e mostrarei, em breve narrativa, porque e como foi composto o lai que assim foi chamado" (MARIE DE FRANCE apud FURTADO, 2001, p. 115). A ambientação da aventura, bem como a descrição dos acontecimentos que antecedem o desfecho da pequena narrativa giram em torno dessa concepção de um acontecimento central. Naturalmente, a manutenção da tensão narrativa será diferente nos lais

\footnotetext{
${ }^{5}$ De acordo com Michèle Gally (2009, p. 13), a forma breve do lai de Marie de France caracteriza-se por grande riqueza linguística. Nas criações da autora francesa encontramse palavras de origem normandas, bretãs, termos da tradição escrita religiosa, da língua oral (ou língua romana rústica) e da langue d'oïl.
} 
mais longos, os quais podem chegar a 1182 versos, do que nos mais breves, de cerca de 118 versos. Toda a estrutura dessa forma breve tem como sustentáculo a questão do episódio ou acontecimento significativo. O recorte que Marie faz do episódio central e a delimitação do espaço da narrativa deixam que a audiência percorra na imaginação os espaços internos das casas fortificadas, os jardins e pomares cercados, também chamados de vergéis, as torres, e outros lugares aprazíveis ou não. A fortificação é proteção do mundo estranho e perigoso, aparecendo em diversos lais. Do mesmo modo, a casa fortificada, erguida sobre um rochedo, cercada por um fosso, por uma sebe de espinhos e, além disso, a floresta solitária e densa fazem parte dos cenários dessa forma breve. Mesmo em lais nos quais a matéria não é propriamente o amor, mas algum episódio maravilhoso, a floresta surge como um dos elementos que emprestam verossimilhança ao narrado, como no Lai do Garwaf ou Homem-Lobo:

Ouvia-se outrora, e costumava acontecer com frequência, que muitos homens se transformavam em garwaf e passavam a habitar nos bosques. O garwaf é besta selvagem; enquanto está em fúria, devora homens, faz grande mal, vive e vagueia pelas grandes florestas (MARIE DE FRANCE apud FURTADO, 2001, p. 75).

Encontramos na estrutura dos lais de Marie de France procedimentos literários que mais tarde tornam-se centrais nas formas breves modernas como a novela e o conto: a brevidade no relato, a direcionalidade do narrado, a redução da aventura a apenas um episódio, a economia nas descrições, o entrecruzar do maravilhoso e do real, a peripécia ou reviravolta do destino. Em termos de criação artística e da matéria propriamente autoral, de acordo com Furtado (2001, p. 26), as diversas faces do amor e a homogeneidade estrutural são elementos que sugerem uma grande contribuição pessoal de Marie de France. A tese da unicidade na autoria e a originalidade nos lais de Marie de França podem ser corroboradas pelo fato de que existe uma estrutura claramente delineada que perpassa todos os doze lais atribuídos à autora francesa, de modo que "a despeito da grande variedade de situações ditadas pela escolha da aventura, a estrutura que ela dá aos lais se mantém homogênea" (FURTADO, 2001, p. 23). Marie de France também incorpora em seus lais a matéria de diversos romances e outras aventuras amorosas presentes no imaginário do século XII, como a história de Tristão e Isolda. Essa narrativa exercera grande fascínio nos trovadores 
do século XII, não apenas pela consagração do encontro e da união dos enamorados, mas por meio de temáticas como: a ferida amorosa, a cura através da dama, a separação dos amantes após serem descobertos e a importância do mar e da travessia marítima (CARMONA, 1998, p. 85). Características como a autenticidade dos fatos narrados, a escolha do assunto, a brevidade da narrativa ou ainda a própria fábula narrada, são fundamentais para o entendimento desta pequena forma de narrativa em verso (DUBUIS, 1973, p. 319).

\section{O maravilhoso nos lais de Marie de France}

A presença do maravilhoso nos lais de Marie de France tem normalmente a função narrativa de resolver a intriga amorosa, servindo como instrumento de conciliação ou aproximação dos amantes. Esse tipo de aparição sobrenatural não tem o mesmo caráter problemático que assumirá séculos mais tarde no romantismo, isto é, como um maravilhoso que porta traços ou fundamentos psicológicos, sendo denominado por alguns autores como fantástico. Por outro lado, as narrativas de Marie de France aproximam-se dos contos de fadas, no sentido que lhes confere Tzvetan Todorov (1975, p. 60), ou seja, como "uma das variedades do maravilhoso" ${ }^{6}$. Inserido pela autora de forma pontual, enquanto técnica narrativa, o maravilhoso fornece os meios necessários para direcionar a história no âmbito da aventura e da concretização do amor. É exatamente a naturalidade de seu aparecimento em meio ao mundo real que caracteriza a diferença entre o maravilhoso e o fantástico:

O universo do maravilhoso está naturalmente povoado de dragões, de unicórnios e fadas; os milagres e metamorfoses ali são contínuos; a varinha mágica é de uso corrente; os talismãs, os gênios, os elfos e os animais agradecidos abundam; as madrinhas satisfazem em um segundo o desejo das órfãs merecedoras de ajuda [...]. No fantástico,

\footnotetext{
${ }^{6}$ Sobre a aproximação entre as narrativas breves e o maravilhoso, Tzvetan Todorov (1975, p. 60) afirma: "Relaciona-se geralmente o gênero maravilhoso ao do conto de fadas; de fato, o conto de fadas não é senão uma das variedades do maravilhoso e os acontecimentos sobrenaturais aí não provocam qualquer surpresa: nem o sono de cem anos, nem o lobo que fala, nem os dons mágicos das fadas (para citar apenas alguns elementos dos contos de Perrault). O que distingue o conto de fadas é uma certa escritura, não o estatuto do sobrenatural".
} 
ao contrário, o sobrenatural aparece como uma ruptura da coerência universal. O prodigioso se mostra aqui como uma agressão proibida, ameaçadora, que rompe a estabilidade de um mundo no qual as leis haviam sido consideradas, até então, como rigorosas e imutáveis (CAILLOIS, 1966, p. 11, tradução nossa).

A questão da veracidade implícita nas aventuras é outro fator característico dessa forma breve. O maravilhoso, como parte intrínseca da aventura, não lhe retira o tom de verossimilhança, pelo contrário, ambos podem conviver harmoniosamente, "de modo que os fatos narrados podem ser tanto verdadeiros como excepcionais" (DUBUIS, 1973, p. 350, tradução nossa). Ao enfatizar que narra aventuras verdadeiras e fatos realmente acontecidos, Marie de France empresta ao narrado um aspecto verossímil, o qual se fundamenta, entre outros fatores, na ancoragem espaço-temporal da narrativa. $\mathrm{O}$ espaço caracterizado nos lais é o âmbito do protegido, como no caso das fortificações, dos bosques e vergéis. $\mathrm{O}$ pomar é o local perfeito para os encontros amorosos:

Lugar íntimo por excelência desde que os amantes o tomam só para si, o pomar é um lugar frágil, o ponto focal do olhar indiscreto e hostil [...] Independentemente de sua função simbólica como lugar secreto dos amores corteses, bem distantes também desses pomares que se oferecem à transgressão e que brincam ao mesmo tempo com a sedução e o perigo, certos pomares se oferecem como paisagens encantadas onde a invenção do homem se amalgama à natureza e a enriquece. Teatro dos sentidos, encenação de um gozo e de uma festa perpétua, o jardim do artifício nascido da tradição do locus amoenus (RÉGNIERBOHLER, 2012, p. 235).

Além de ser o local de encontro e deleite amoroso, a funcionalidade do pomar cercado e íntimo relaciona-se a fatores como a restrição do acesso a qualquer indivíduo e a proteção contra os perigos exteriores. A grande ausência de liberdade em um mundo completamente fechado é outro fator que justifica o uso de cenas aventureiras e bucólicas nos lais de Marie de France. Georges Duby (DUBY; ARIÈS 2012, p. 536) afirma que as obras romanescas do século XII cumpriam ainda a função de incitar a imaginação através das imagens de acontecimentos e lugares maravilhosos. Entre os 
principais lugares utilizados para a ação romanesca, a floresta remetia às provas de aventura, o que emprestava às canções e romances um ar de liberdade e autonomia com o qual esses indivíduos apenas poderiam sonhar. O que ocorre é que "essas obras põem em cena no imaginário aquilo que os homens jovens que constituíam a parte mais receptiva do auditório estavam privados, exaltando o desabrochar do indivíduo e celebrando sua liberação" (DUBY; ARIÈS 2012, p. 536).

Assim como o procedimento de ancoragem espaço-temporal tem a função de emprestar verossimilhança à narrativa, o maravilhoso se insinua de modo natural nos lais. Pelo fato de que o sentimento místicomaravilhoso era muito intenso entre os indivíduos da época de Marie de France, nada havia (do ponto de vista da verossimilhança) que impedisse a aparição ex nihilo de algum elemento maravilhoso na narrativa. A autora insere o maravilhoso de um modo muito espontâneo, sem causar qualquer espanto que desvie a atenção do leitor ou audiência. Um exemplo desse procedimento encontra-se no Lai Yonec. Uma bela dama é trancada pelo ciumento marido na torre da fortificação e chora a infelicidade de seu destino, clamando aos céus por solução para sua tormenta. Quando tudo parece perdido, eis que um ser maravilhoso surge, possibilitando a resolução da aventura amorosa:

No instante em que ela assim terminava seu lamento, divisou a sombra de uma grande ave através de uma janela estreita; ela não sabia o que poderia ser. Entrou no quarto, voando; levava correias nos pés, parecia um açor de cinco ou seis mudas. Pousou diante da dama. Depois de ficar ali um pouco, enquanto ela o contemplava, transformou-se em um cavaleiro belo e nobre. A dama ficou estarrecida; $o$ sangue lhe subiu ao rosto e estremeceu, teve grande pavor, cobriu a cabeça. O cavaleiro foi muito cortês, primeiro lhe dirigiu a palavra: - Dama, não tenhais medo: o açor é pássaro gentil [...] Depois de rirem e brincarem bastante e de trocarem confidências, o cavaleiro despediu-se (MARIE DE FRANCE apud FURTADO, 2001, p. 102).

No caso da narrativa breve do lai, o surgimento do maravilhoso podia remeter às tradições dos bretões, dos celtas ou do imaginário cristão, mas não havia ali a consciência de que se estava ultrapassando os liames da vida cotidiana e suas limitações. A busca pela manutenção das regras do jogo narrativo, a criação de um ambiente propício e o viés 
de veracidade são características dessa forma breve. Nessa configuração, o papel da delimitação do episódio significativo em torno da aventura a ser narrada é imprescindível. Embora a aparição do acontecimento maravilhoso nas narrativas ultrapasse as fronteiras do humano, os lais de Marie de France mantêm, na maioria dos casos, a humanização dos elementos sobrenaturais. Mesmo quando a transformação maravilhosa se dá por efeito de alguma traição, como no Lai do Homem-Lobo, o desfecho da fábula ocorre em nome do amor. A metamorfose do animal quase sempre se concretiza na forma do ser amado, pois a finalidade da aventura é o encontro amoroso. Por outro lado, não se trata de mero pacto ficcional entre a autora e sua audiência, o qual permitiria que o público acreditasse no surgimento do elemento sobrenatural em meio ao cotidiano, mas sim na crença efetiva de que o amor pode ser forte o suficiente para causar a aproximação entre o real e o maravilhoso:

A janela é estreita, a torre é alta. Lá dentro uma dama suspira sua solidão. Uma grande ave entra pela janela, transforma-se num cavaleiro, e diz à dama que sempre a amou e muito a desejou em seu coração, que nunca amou nem amará outra que não ela. Assim é o amor nos lais de Maria de França. Uma força que está no ar, a caminho, poder de metamorfose que mudará para sempre a vida dos seus protagonistas (COLASANTI apud FURTADO, 2001, p. 9).

O surgimento do maravilhoso nos lais de Marie de France demonstra que o sobrenatural pode também se constituir em forma exemplar de punição, castigo ou redenção das personagens. Em suas narrativas, a autora chama a atenção para as sérias consequências de se ignorar os códigos de conduta da Corte e as leis do amor. Seja enquanto procedimento literário que concede intensidade à narrativa, como resolução das intrigas amorosas ou fórmula exemplar, a utilização do maravilhoso relaciona-se intimamente à manutenção da unidade dramática da narrativa.

\section{Conclusão}

Em razão de seu caráter eminentemente oral, os lais carregam em sua estrutura certos aspectos que serão encontrados em outras formas breves, como ofabliau, a novela, a fábula e o conto: a concisão na descrição de personagens, a economia no narrado, a direcionalidade intencional da fábula em torno de um episódio central, a restrição espaço-temporal, 
entre outros elementos. A intensidade de efeito desse tipo de narrativa é conseguida tanto pelos elementos formais presentes na estrutura das obras, quanto pelo conteúdo da matéria narrada. Marie de France mescla a temática do maravilhoso bretão e celta àquele proveniente do imaginário cristão, em uma verdadeira riqueza de descrições. Sua obra espelha toda a variedade cultural e linguística e o intercâmbio entre povos que ocorria no século XII. Destinadas ao ambiente mundano cortês, os lais de Marie de France são parte integrante de um mundo de aventuras maravilhosas, de combates sangrentos, de peregrinações em nome da fé, de florestas encantadas cheias de perigo e deleites, e da busca pela correspondência no amor. É nesse mundo distante, estranho e singelo, em meio ao qual o real e o maravilhoso se confundem, que ecoa a voz de Marie de France.

\section{Referências}

AQUATI, C. Posfácio. In: PETRÔNIO. Satíricon. São Paulo: Cosac Naify, 2008. p. 223-239.

AUBRIT, J-P. Le Conte et la nouvelle. Paris: Armand Colin, 2002.

AUERBACH, E. Mimesis: a representação da realidade na literatura ocidental. São Paulo: Perspectiva, 2004.

CAILLOIS, R. Images, images. Paris: Corti, 1966.

CARMONA, F. El lai: narración corta y narración lírica. In: PAREDES, J. G. (Org.). Tipología de las formas narrativas breves románicas medievales. Granada: Universidad de Granada, 1998. p. 83-102.

DUBUIS, R. Les Cent nouvelles nouvelles et la tradition de la nouvelle en France au Moyen Age. Grenoble: Presses Universitaires de Grenoble, 1973.

DUBY, G.; ARIÈS, P. (Org.). História da vida privada: da Europa feudal à Renascença. São Paulo: Cia. das Letras, 2012. v. 2.

FERRANTE, J. M. Marie de France. In: HOLLIER, D. A New History of French Literature. Cambridge: Harvard University Press, 2001. p. 48-65.

FURTADO, A. L. Lais de Maria de França. Petrópolis: Editora Vozes, 2001.

GALLY, M. Chrétien de Troyes: Perceval ou le conte du Graal. Paris: Larousse, 2009. 
HOEPFFNER, E. Les Lais de Marie de France. Paris: Boivin et C. Éditeurs, 1935.

LE GOFF, J. A civilização do Ocidente medieval. Bauru: EDUSC, 2002. MICHA, A. Lais féeriques des XII et XIII ${ }^{e}$ siècles. Paris: Flamarion, 1992.

MOISES, Massaud. Dicionário de termos literários. São Paulo: Cultrix, 2004.

PAREDES, J. G. (Org.), Tipología de las formas narrativas breves románicas medievales. Granada: Universidad de Granada, 1998.

PETRÔNIO. Satíricon. São Paulo: Cosac Naify, 2008.

POTTIER, Bernard. Textes médiévaux français et romans. Paris: Éditions Klincksieck, 1964.

RÉGNIER-BOHLER, D. Exploração de uma literatura. In: DUBY, G.; ARIÈS, P. História da vida privada: da Europa feudal à Renascença. São Paulo: Cia. das Letras, 2012. p. 313-410.

TARNAPOLSKY, H. A canção de Rolando. Tradução de Ligia Vassalo. Rio de Janeiro: Livraria Francisco Alves, 1988.

TODOROV, T. Introdução à literatura fantástica. São Paulo: Perspectiva, 1975.

ZUMTHOR, P. Essai de poétique médiévale. Paris: Éditions du Seuil, 1972. 
